\title{
Fastlegenes arbeidstid 2000-08
}

\author{
Sammendrag \\ Bakgrunn. Det finnes lite pålitelig \\ informasjon om fastlegenes arbeidstid. \\ Formålet med vår undersøkelse var \\ å beskrive ukearbeidstidens utvikling \\ fra 2000 til 2008 for norske allmenn- \\ leger samt listelengde og opplevd \\ arbeidsbelastning.
}

\section{Materiale og metode. Allmennleger/} fastleger i Forskningsinstituttets referansepanel anga i 2000, 2002, 2004, 2006 og 2008 sin ukentlige arbeidstid og i 2002 og 2008 listelengde. Vi benyttet ikke-overlappende $95 \%$ konfidensintervaller til testing av gruppeforskjeller i intervallvariabler og proporsjoner.

Resultater. Mellom 227 og 316 allmennleger/fastleger svarte hver gang. Gjennomsnittlig ukearbeidstid var 45,1 timer ( $95 \% \mathrm{KI}$ 43,6-46,5 timer) i 2000 og 46,4 timer ( $95 \%$ KI 45,2-47,6 timer) i 2008. For kvinnelige allmennleger $ø$ kte timetallet, mens mannlige allmennleger hadde omtrent det samme timetallet i 2000 som i 2008. Gjennomsnittlig listelengde i 2002 og 2008 var 1325 og 1278 for mannlige og 1155 og 1144 for kvinnelige fastleger. Andelen som opplevde at de arbeidet under et uakseptabelt arbeidspress, gikk signifikant ned fra $38,1 \%$ i 2000 til $25,5 \%$ i 2008.

Fortolkning. Ukearbeidstiden for allmennleger har $ø$ kt med omtrent en time fra 2000 til 2008, og det er de kvinnelige allmennlegene som står for økningen. Nedgangen i andelen som opplever et uakseptabelt arbeidspress tror vi henger sammen med at fastlegeordningen har gitt legene bedre kontroll over sin egen arbeidsbelastning.

\section{Olaf G. Aasland}

olaf.aasland@legeforeningen.no

Legeforeningens forskningsinstitutt og

Avdeling for helseledelse og helseøkonomi Institutt for helse og samfunn Universitetet i Oslo

\section{Judith Rosta}

Legeforeningens forskningsinstitutt

Norske leger har lengre arbeidsuker enn de fleste andre yrkesgrupper $(1,2)$, men er også gjennomgående svært tilfredse i jobben (3). En sammenlikning av tyske og norske sykehusleger viste at de norske legene var statistisk signifikant mer fornøyde med arbeidstiden sin enn de tyske (4). Sykehusleger har i stor grad regulert arbeidstid som det er lett å måle objektivt, og det finnes en rekke studier der sykehuslegenes arbeidstid og arbeidstidsmønster er brukt som forklaringsvariabler, både når det gjelder pasientsikkerhet (5) og legenes egen helse og velvære $(6,7)$.

I motsetning til sykehuslegene regulerer privatpraktiserende leger i stor grad arbeidstiden sin selv, og det finnes ikke andre opplysninger om ukearbeidstid og arbeidstidsmønster enn det legene selv oppgir. Da fastlegeordningen ble innført i 2001, innebar det en betydelig standardisering av allmennlegenes arbeidsforhold, der hovedvariabelen er antall pasienter på listen. Vi vet nøyaktig hvor mange pasienter fastlegen skal betjene, men vi vet lite om hvor mye tid den enkelte bruker på pasientene sine. I en tidligere studie har vi vist at fastlegeordningen ikke i særlig grad påvirket allmennlegenes jobbtilfredshet, som i utgangspunktet er vesentlig høyere enn sykehuslegenes (8). Men har innføringen av fastlegeordningen hatt noen innflytelse på allmennlegenes ukearbeidstimer? Tidligere undersøkelser antyder forskjellige svar. Grytten og medarbeidere viste at omfanget av kurativ virksomhet for norske allmennleger gikk ned med 2,2 timer per uke fra 1998 til 2003, men i denne undersøkelsen var det ingen opplysninger om total ukearbeidstid, og de to utvalgene var lite sammenliknbare (9). Norsk forening for allmennmedisin skrev i en høringsuttalelse i forbindelse med en strategiplan for arbeid og psykisk helse at allmennlegenes ukearbeidstid hadde økt med 6-7 timer etter innføringen av fastlegeordningen i 2001, til ca. 49 timer per uke (10), men datagrunnlaget for denne opplysningen er uklart.

Formålet med denne artikkelen er å beskrive utviklingen i allmennlegenes samlede ukearbeidstid basert på data fra 2000, 2002, 2004, 2006 og 2008, hvor stor andel av tiden som går med til direkte pasientkontakt, endringer i listelengde, opplevd arbeidspress og i hvilken grad fastlegene ønsker høyere eller lavere arbeidsbelastning.

\section{Materiale og metode}

Data kommer fra Forskningsinstituttets referansepanel, et tilnærmet representativt utvalg på ca. 1600 yrkesaktive leger som annethvert år siden 1994 er fulgt med postale spørreskjemaer. I denne artikkelen benyttes data fra 2000, 2002, 2004, 2006 og 2008. Som vist i figur 1 er det ganske stor utskiftning i allmennlegegruppen fra gang til gang. Dette skyldes at noen blir pensjonister eller trekker seg fra panelet og at en del skifter jobb. Dessuten svarer ikke alle paneldeltakere på undersøkelsen hver gang. I 2008 ble panelet utvidet med en tilfeldig gruppe yngre leger som hadde fătt autorisasjon etter 2000 , og 33 av disse oppga at de var fastleger. 119 leger, 32 kvinner og 87 menn, var allmennleger i 2000 og fastleger i 2008 og utgjør en «veterangruppe». For å vurdere utvalgets representativtet $\mathrm{i}$ forhold til alder, kjønn og bosted, samt anslå svarprosent, benyttet vi også data fra Legeforeningens Internett-baserte statistikkbank (11).

\section{Spørsmål om tidsbruk}

Nokså identiske spørsmål om tidsbruk er benyttet på alle fem spørretidspunkter. I 2000, 2002 og 2004 spurte vi: «I en gjennomsnittlig arbeidsuke, omtrent hvor mange timer bruker du på: Pasientarbeid, møtevirksomhet, papirarbeid, telefoner etc., til sammen?»

\section{Hovedbudskap}

- Fastlegenes gjennomsnittlige ukearbeidstid økte fra 2000 til 2008, men bare blant kvinnelige leger

- Direkte pasientarbeid utgjør ca. $70 \%$ av den totale ukearbeidstiden. Dette har vært uendret siden 2000

- Andelen som synes de har et uakseptabelt arbeidspress, har gått ned

- To av tre fastleger ønsker seg kortere arbeidsuke 
Spørsmålene var satt opp slik at legen både skulle angi antall timer på hver av komponentene, men også ved å summere selv komme frem til totalt antall arbeidstimer per uke.

For å øke presisjonen formulerte vi i 2006 spørsmålet slik: «I en gjennomsnittlig arbeidsuke, inkludert ev. bistillinger, omtrent hvor mange timer bruker du på: ...»

I 2008 ble igjen presisjonsnivået økt, da føyde vi til både kvalifiserende beskrivelse på hver tidskomponent samt mulighet for å sette opp timer på henholdsvis faglig oppdatering og annet. Hele spørsmålskomplekset ble da som fremstilt i tabell 1 .

I 2004 og 2006 skulle legene angi om de var spesialister i allmennmedisin. I 2002 og 2008 spurte vi de som var fastleger om hvor mange pasienter de hadde på listen. I 2000, 2004 og 2008 fikk legene også følgende spørsmål: «Angi hvor ofte du arbeider under et uakseptabelt arbeidspress.» Svaralternativene var aldri, sjelden, iblant, nokså ofte, og ofte.

Endelig stilte vi i 2008 følgende spørsmål: «Hvis du kunne velge og ikke trengte å ta økonomiske hensyn, ville du: jobbet mindre enn i dag, jobbet omtrent like mye som i dag, jobbet mer enn i dag?»

\section{Analyser}

Vi presenterer data fra de legene som på hvert av de fem tidspunktene anga at de var allmennlege/fastlege. Vi benytter gjennomsnittsverdier til å beskrive sentraltendens og til gruppesammenlikninger. Det er gjort en korrelasjonsanalyse mellom listelengde og opplevd arbeidspress. Testing av statistisk signifikans ble gjort ved å vurdere om $95 \%$ konfidensintervallene overlappet, både for proporsjoner (prosenter) og for intervallvariabler (alder, listelengde, timer per uke). Kvinner og menn er stort sett analysert hver for seg.

\section{Estimering av svarprosent}

Dessverre er det ikke mulig å beregne svarprosent for hvert tidspunkt siden vi ikke vet hvor mange allmennleger/fastleger som ikke svarte hver gang. Vi har i stedet sammenliknet andelen responderende allmennleger/fastleger av alle respondenter med andelen yrkesaktive medlemmer av Allmennlegeforeningen av alle yrkesaktive leger (tab 2).

\section{Resultater}

Hvert av årene oppga mellom 227 og 316 av respondentene at de hadde hovedstilling $\mathrm{i}$ allmennmedisin eller var fastlege (fig 1). 195 av $257(76 \%)$ i 2004 og 172 av 227 (76\%) i 2006 oppga dessuten at de var spesialister i allmennmedisin. Både i 2000 og i 2008 var det 247 allmennleger/fastleger i utvalget, hvorav 119 hadde en slik jobb på begge tidspunkter.

\section{Svarprosent}

Andelen allmennleger/fastleger blant respondentene var lavere enn andelen med-

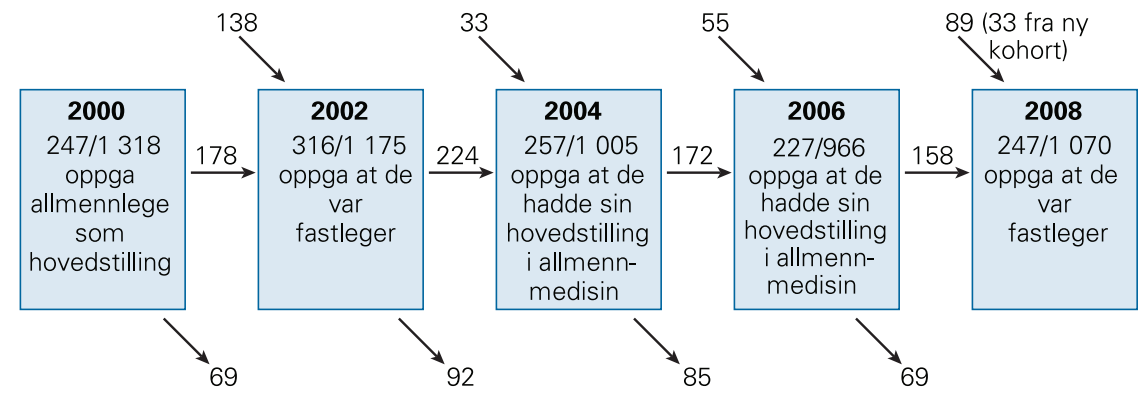

Figur 1 Antall responderende allmennleger/fastleger i Legeforeningens referansepanel 2000-08. Tilgang stabilitet og avgang. Brøkene i boksene angir antall respondenter blant henholdsvis allmennleger/fastleger og alle i referansepanelet lemmer i Allmennlegeforeningen av alle yrkesaktive leger i 2000 og høyere i 2002, mens det i 2004, 2006 og 2008 ikke var statistisk signifikant forskjell (tab 2).

\section{Alder og kjønn}

Tabell 2 viser også utvalgets representativitet i forhold til alder og kjønn. Gjennomsnittsalderen for de fastlegene som svarte i 2008 var 50,1 år (95\% KI 49,0-51,3 år), 47,6 år (95\% KI 45,5-49,7 år) for kvinner og 51,3 år (95\% KI 50,0-52,7 år) for menn. Gjennomsnittsalderen for alle yrkesaktive fastleger i Norge i slutten av 2008 var 47,4 år, noe som betyr at vårt utvalg var ca. 2,5 år eldre i gjennomsnitt.

Kvinneandelen i vårt utvalg varierer rundt $30 \%$, og gikk opp til $31,6 \%(95 \% \mathrm{KI}$ 25,9-37,8) etter at panelet ble utvidet med en gruppe yngre leger i 2008, noe som ikke er statistisk signifikant forskjellig fra kvinneandelen av alle yrkesaktive allmennleger i Norge (35,5\% i 2008).

\section{Bosted}

Det var ingen statistisk signifikant forskjell fordelt etter de opprinnelige fem helseregionene sammenliknet med bostedet til alle norske fastleger (data ikke vist).

\section{Samlet arbeidstid}

Figur 2 viser endring i gjennomsnittlig antall ukearbeidstimer med $95 \%$ konfidensintervall over hele perioden for kvinner og for mellom respondentenes bosted i 2008 menn. Som det fremgår lå kvinnene statistisk signifikant lavere enn mennene i 2000, 2002, 2004 og 2006, men ikke i 2008. I 2000 var det 45 av $72(62,5 \%)$ kvinnelige allmennleger som arbeidet 37,5 timer i uken eller mer, i 200863 av $77(81,8 \%$ ) (endring ikke statistisk signifikant). Tilsvarende tall for mannlige allmennleger/fastleger var 148 av $173(85,5 \%)$ i 2000 og 153 av 169 (90,5\%) i 2008 (endring ikke statistisk signifikant).

\section{Arbeidstidskomponenter}

Tabell 3 viser alle arbeidstidskomponentene for kvinnelige og mannlige fastleger i 2008. Den interne fordelingen var omtrent lik i de foregående årene, bortsett fra at vi da ikke spurte eksplisitt om faglig oppdatering (data ikke vist). Andelen av total ukearbeidsstid brukt til pasientarbeid var meget stabil og varierte mellom $70 \%$ og $72 \%$, og det var ingen kjønnsforskjell.

\section{Listelengde}

Gjennomsnittlig listelengde i $2002(\mathrm{n}=312)$ var 1275 (95\% KI 1 231-1319), 1155 (1 079-1 230) for kvinnelige og 1325 (1 272-1 377) for mannlige fastleger. Korteste liste var på 150 , lengste på 2600 . Tilsvarende tall for $2008(\mathrm{n}=243)$ var 1236 (1 191-1 282), 1144 (1 068-1 219) for kvinner og 1278 (1 222-1 334) for menn. Korteste liste var 480, lengste 2 500. Gjennomsnittlig forskjell i listelengde mellom kvinnelige og mannlige fastleger går ned fra 170 til 134.
Tabell 1 Spørsmål om arbeidstid til fastleger i Legeforeningens referansepanel i 2008. I en gjennomsnittlig arbeidsuke, inkludert vakter og ev. bistilling(er), omtrent hvor mange timer bruker du på

\section{Pasientarbeid}

lall direkte kontakt med enkeltpasienter eller deres pårørende, inkludert telefoner, e-post etc.)

Møtevirksomhet

Itverrfaglige teammøter, journalmøter, veiledningsmøter etc.

\section{Papirarbeid, telefoner}

(journaler, attester, epikriser etc.)

Faglig oppdatering

Annet, skriv:

Til sammen

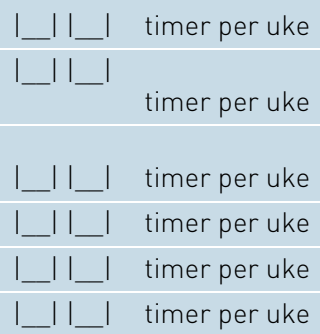


Tabell 2 Utvalgets representativitet i forhold til andel allmennleger, kjønn og alder

\begin{tabular}{|c|c|c|c|c|c|c|c|c|}
\hline \multirow[b]{2}{*}{$\AA ̊ \AA r$} & \multicolumn{4}{|c|}{ Våre respondenter } & \multicolumn{4}{|c|}{ Alle yrkesaktive allmennleger } \\
\hline & $\begin{array}{c}\text { Antall } \\
\text { allmennleger/ } \\
\text { antall } \\
\text { respondenter }\end{array}$ & $\begin{array}{l}\text { Andel } \\
\text { allmennleger } \\
\text { (95\% KI) }\end{array}$ & $\begin{array}{l}\text { Alder (år), } \\
\text { gjennomsnitt }\end{array}$ & $\begin{array}{c}\text { Kvinneandel } \\
(\%)\end{array}$ & $\begin{array}{l}\text { Antall medlem- } \\
\text { mer i Allmenn- } \\
\text { legeforeningen/ } \\
\text { alle leger }\end{array}$ & $\begin{array}{l}\text { Andel medlem- } \\
\text { mer i Allmenn- } \\
\text { legeforeningen }\end{array}$ & $\begin{array}{l}\text { Alder (år), } \\
\text { gjennomsnitt }\end{array}$ & $\begin{array}{c}\text { Kvinneandel } \\
{[\%]}\end{array}$ \\
\hline 2000 & 247/1 318 & $18,7(16,7-21,0)$ & 46,4 & 29,6 & $3200 / 14359$ & 22,3 & 46,1 & 28,6 \\
\hline 2002 & $316 / 1175$ & $26,9(24,4-29,5)$ & 48,0 & 28,6 & $3702 / 16161^{1}$ & $22,9^{1}$ & $46,3^{1}$ & $30,0^{1}$ \\
\hline 2004 & $257 / 1005$ & $25,6(22,9-28,4)$ & 49,4 & 28,2 & $3777 / 16116$ & 23,4 & 46,8 & 31,5 \\
\hline 2006 & $227 / 966$ & $23,5(20,9-26,3)$ & 50,9 & 28,8 & $3877 / 17568$ & 22,1 & 47,1 & 33,4 \\
\hline 2008 & $247 / 1070$ & $23,1(20,6-25,8)$ & 50,1 & 31,6 & $4322 / 18919$ & 22,8 & 47,4 & 35,5 \\
\hline
\end{tabular}

\section{Arbeidspress}

I 2000 anga 38,1\% (94/247) av allmennlegene at de nokså ofte eller ofte opplevde at de drev under et uakseptabelt arbeidspress. I 2004 var tilsvarende andel 33,3\% (80/240) (17 svarte ikke på spørsmålet), mens den i 2008 var 25,5\% (63/247). Forskjellen mellom 2000 og 2008 er statistisk signifikant. Det var ingen statistisk signifikante kjønnsforskjeller i opplevelsen av uakseptabelt arbeidspress, og ingen sammenheng mellom en slik opplevelse og listelengde (data ikke vist).

\section{Ønske om endring $i$ arbeidsbelastning}

165 av $245(67 \%)$ svarte at de ønsket å jobbe mindre enn i dag, 79 av 245 (32\%) ville jobbet omtrent like mye. Bare én kvinnelig fastlege ønsket å jobbe mer. To svarte ikke på spørsmålet.

\section{Diskusjon}

Studien viser at den totale arbeidstiden for allmennlegene/fastlegene har økt med omtrent en time fra 2000 til 2008, og at det er de kvinnelige legene som står for økningen. For dem har den ukentlige arbeidstiden økt med fem timer, mens de mannlige har en tilnærmet uendret ukearbeidstid i perioden.

Det kan se ut som om en vesentlig grunn til denne økningen er at mange kvinner går over fra å arbeide deltid (under 37,5 timer i

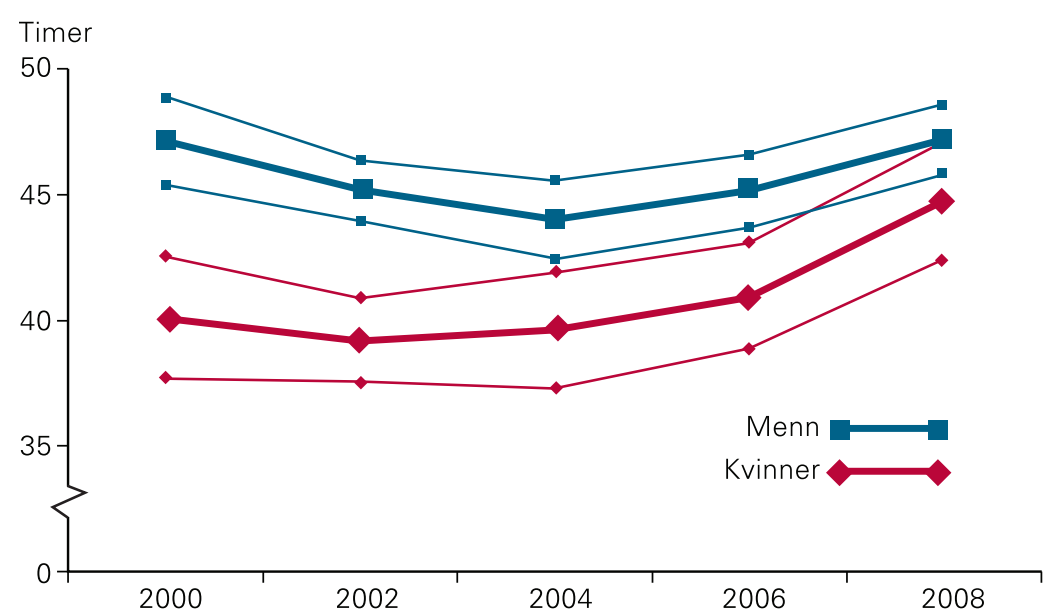

Figur 2 Gjennomsnittlig ukearbeidstid for kvinnelige og mannlige allmennleger/fastleger med $95 \%$ konfidensintervall, 2000-08 uken) til heltid (37,5 timer eller mer). Dette er i så fall i tråd med utviklingen i befolkningen generelt, som viser at kvinner bruker mer tid i yrkeslivet enn før, selv om det samtidig er en nedgang $i$ arbeidstid blant småbarnsmødre (12). I den aktuelle perioden økte de kvinnelige veteranenes gjennomsnittsalder fra 43 år til 51 år (data ikke vist), som sannsynligvis innebærer at nødvendig tid til omsorg for små barn reduseres, med mulighet til lengre arbeidsuke og økt listelengde.

Leger har generelt lange arbeidsuker (1, $2,6,7)$. Fastleger jobber antakelig mer enn de fleste andre yrkesgruppene her i landet, selv om en slik sammenlikning må gjøres med forbehold. I 2005 var for eksempel andelen yrkesaktive i befolkningen som jobbet over 48 timer per uke $6 \%$ (13), mens den tilsvarende andelen for våre respondenter $\mathrm{i}$ 2004 var $28 \%$ (69/250). I 2008 hadde norske yrkesaktive en gjennomsnittlig avtalt arbeidsuke på 34,3 timer (14), mens våre 246 fastleger i 2008 hadde en gjennomsnittlig arbeidsuke på 46,4 timer. I en undersøkelse blant allmennleger i 11 land i 2009 fant Kunnskapssenteret at en gruppe på 774 norske fastleger (svarprosent 56) som fikk spørsmålet «Hvor mange timer jobber du som fastlege per. uke?» anga gjennomsnittlig 40,4 timer, mot f.eks. 37,8 timer i Sverige eller 48,6 timer i Frankrike (15). Forskjellen

på seks timer mellom vår undersøkelse og denne kan skyldes at våre leger også inkluderte andre legeoppgaver enn rent fastlegearbeid i sine timeangivelser.

Studiens styrke er at den dels er basert på gjentatte målinger fra de samme fastlegene $\mathrm{i}$ 2000, 2002, 2004, 2006 og 2008. Det gjør det også mulig å vurdere i hvilken grad innføringen av fastlegeordningen i $2001 \mathrm{kan}$ ha påvirket legenes ukearbeidstid.

Men det finnes også svakheter. På grunn av at studien er kohortbasert, vil ikke de fastlegene som svarer til enhver tid være fullstendig representative for alle fastleger. Men forskjellene er små, og ulempen oppveies langt på vei av fordelen som ligger i de gjentatte målingene. Respondentenes alder avspeiler også at det dreier seg om to kohorter, én med leger som fikk autorisasjon før 2000, der de fleste over 70 år etter hvert går ut, og én med leger som fikk autorisasjon etter 2000. En del leger går dessuten inn i og ut av jobben som allmennlege over en åtteårsperiode. Vi har også estimert ukearbeidstiden ved hjelp av generell lineær modellering (GLM) med gjentatte målinger for dem som svarte ved alle fem tidspunkter (data ikke vist), og fant tilnærmet de samme verdiene som ved de presenterte uavhengige målingene.

Selvrapportert arbeidstid kan selvsagt avvike fra reell arbeidstid. Hvorvidt det $\mathrm{i}$ vårt utvalg er en tendens til å overvurdere eller undervurdere egen arbeidstid (16), eller om det finnes kjønnsrelaterte forskjeller i selvrapportering, vet vi ikke. Presisjonsnivået for spørsmålene om de forskjellige arbeidstidskomponentene økte som nevnt i 2006 (bistillinger nevnes eksplisitt) og i 2008 (også vaktarbeid nevnes). Det er imidlertid grunn til å tro at de fleste respondentene også har tatt med disse komponentene tidligere, først og fremst fordi spørsmålene hele tiden har vært stilt på en slik måte at det går tydelig frem at vi ønsker angivelse av total ukearbeidstid. Eksempelvis tilsvarer tiden som brukes til «faglig oppdatering», som det bare ble spurt om i 2008, til en tilsvarende reduksjon i tiden for «papirarbeid» i 2006 (data ikke vist). Den forholdsvis stabile angivelsen av samlet arbeidstid og andel direkte pasient- 


\begin{tabular}{|c|c|c|c|c|c|}
\hline & & Antall & Gjennomsnitt & Laveste & Høyeste \\
\hline \multirow[t]{3}{*}{ Pasientarbeid } & Kvinne & 78 & 31,23 & 13 & 72 \\
\hline & Mann & 169 & 32,82 & 0 & 60 \\
\hline & Begge & 247 & 32,32 & 0 & 72 \\
\hline \multirow[t]{3}{*}{ Møtevirksomhet } & Kvinne & 78 & 3,57 & 0 & 17 \\
\hline & Mann & 168 & 4,28 & 0 & 40 \\
\hline & Begge & 246 & 4,06 & 0 & 40 \\
\hline \multirow[t]{3}{*}{ Papirarbeid og telefoner } & Kvinne & 78 & 7,22 & 1 & 20 \\
\hline & Mann & 167 & 7,14 & 0 & 30 \\
\hline & Begge & 245 & 7,16 & 0 & 30 \\
\hline \multirow[t]{3}{*}{ Faglig oppdatering } & Kvinne & 74 & 2,45 & 0 & 25 \\
\hline & Mann & 162 & 2,80 & 0 & 19 \\
\hline & Begge & 236 & 2,69 & 0 & 25 \\
\hline \multirow[t]{3}{*}{ Annet } & Kvinne & 7 & 4,43 & 0 & 15 \\
\hline & Mann & 20 & 5,35 & 0 & 36 \\
\hline & Begge & 27 & 5,11 & 0 & 36 \\
\hline \multirow[t]{3}{*}{ Til sammen } & Kvinne & 77 & 44,73 & 21 & 90 \\
\hline & Mann & 169 & 47,17 & 14 & 77 \\
\hline & Begge & 246 & 46,41 & 14 & 90 \\
\hline
\end{tabular}

10. Norsk forening for allmennmedisin. Strategiplan for arbeid og psykisk helse 2007-2012. Høringsuttalelse 25.5.2007. www.legeforeningen.no/id/ 121772.0 (26.3.2009).

11. Den norske legeforening. Legestatistikk. www.legeforeningen.no/id/18 (13.8.2010).

12. Kitterød RH. Han jobber, hun jobber, de jobber. Arbeidstid blant par av små barnsforeldre. Oslo: Statistics Norway, 2005.

13. Aagestad C, Eiken T. Arbeidsmiljøet i Norge og EU - en sammenlikning. Oslo: Nasjonal overvåking av arbeidsmiljø og helse, 2007.

14. Statistisk sentralbyrå. Statistisk årbok 2009. Tabell 209. www.ssb.no/aarbok/tab/tab-209.html (13.8.2010)

15. Holmboe O, Bjertnæs $\emptyset A$, Bukholm G et al. Commonwealth Fund-undersøkelsen i 2009 blant allmennleger: Resultater fra en komparativ unders $\varnothing$ kelse i 11 land. Oslo: Nasjonalt kunnskapssenter for helsetjenesten, 2009

16. Hofoss D, Gjerberg E. Legers arbeidstid. Tidsskr Nor Lægeforen 1994; 114: 3059-63.

17. Skogsholm A, Hasvold T. Er fastlegesystemet mer krevende for kvinnelige enn for mannlige leger? Tidsskr Nor Lægeforen 1999; 119: 3417-20.

Mottatt 6.5. 2010, første revisjon innsendt 14.8. 2010, godkjent 18.11. 2010. Medisinsk redaktør Siri Lunde. arbeid tyder på at legene stort sett har tatt bistillinger og vaktarbeid i betraktning.

Noen bakgrunnsvariabler som kan påvirke arbeidstiden, som for eksempel lokale forskjeller i pasientenes behov for legekontakt $(9,17)$ eller legenes omsorg for egne barn (1), har vi ikke data på i vårt materiale.

Det kan tenkes at økt listelengde gir økt arbeidspress, men det virker ikke som om dette er tilfellet for våre kvinnelige respondenter, i og med at andelen med opplevd tidspress går ned, mens listelengden var tilnærmet stabil. Det er også mulig at noen de legene som øker arbeidstiden, beholder listelengden og dermed reduserer tidspresset. Kortere lister kan gir mer tid til hver pasient og mer tid til andre oppgaver. Dette kan forklare noe av nedgangen i opplevelsen av uakseptabelt arbeidspress i vårt utvalg. Den viktigste forklaringen mener vi imidlertid må være at fastlegeordningen har gitt hver enkelt lege bedre mulighet til kontroll over egen arbeidsbelastning.

\section{Olaf Gjerløw Aasland (f. 1944)}

er lege, leder av Legeforeningens forskningsinstitutt og professor ved Avdeling for helseledelse og helseøkonomi, Institutt for helse og samfunn, Universitetet i Oslo. Han har de siste 20 årene særlig forsket på legenes helse og arbeidsforhold

Ingen oppgitte interessekonflikter.

\section{Judith Rosta (f. 1968)}

er m.a., ph.d. og forsker ved Legeforeningens forskningsinstitutt. Hun har 12 års erfaring med forskning om legers helse og arbeidsforhold, bl.a. initierte hun og ledet den første nasjonale spørreskjemaundersøkelse blant sykehusleger i Tyskland.

Ingen oppgitte interessekonflikter.

\section{Litteratur}

1. Abrahamsen B. Female professionals working hours in the welfare state services. Ergonomia JJE\&HF 2007: 29: 193-7.

2. Aasland OG. Konsekvenser av arbeidstid - en litteraturgjennomgang. Oslo: Legeforeningens forskningsinstitutt, 2008

3. Nylenna M, Aasland OG Jobbtilfredshet blant norske leger. Tidsskr Nor Lægeforen 2010; 130: 1028-31.

4. Rosta J, Nylenna M, Aasland OG. Job satisfaction among hospital doctors in Norway and Germany. A comparative study on national samples. Scand J Public Health 2009: 37: 503-8.

5. Meretoja OA. We should work less at night. Acta Anaesthesiol Scand 2009; 53: 277-9.

6. Rosta J, Gerber A. Excessive working hours and health complaints among hospital physicians: a study based on a national sample of hospital physicians in Germany. Ger Med Sci 2007; 5 Doc09.

7. Wallace JE, Lemaire JB, Ghali WA. Physician wellness: a missing quality indicator. Lancet 2009; 374 $1714-21$.

8. Aasland OG, Rosta J, Nylenna M. Healthcare reforms and job satisfaction among doctors in Norway. Scand J Public Health 2010; 38: 253-8.

9. Grytten J, Skau I, Sørensen RJ et al. Fastlegereformen. En analyse av fastlegenes arbeidsbelastning og tjenestetilbud. Forskningsrapport 11/ 2003. Sandvika: Handelshøyskolen BI, 2003. 